Revista internacional

de Historia

de la Comunicación

\title{
UNA BIBLIOTECA DIGITAL DE PRENSA ANTIGUA. El caso de las relaciones de sucesos sevillanas (siglo XVI-XVIII)
}

DOI: http://dx.doi.org/10.12795/RiHC.2013.i01.01

Francisco Baena - frbaena@us.es

Inmaculada Casas - mincasdel@gmail.com

Má Teresa Cuadros - mteresapacu@hotmail.com

Universidad de Sevilla

Resumen: Esta comunicación informa sobre el trabajo de catalogación, digitalización y difusión en internet que el grupo de investigación en "Historia del periodismo en Andalucia" ha desarrollado en la última década en Sevilla, donde hemos descrito in situ más de 1.200 Relaciones de sucesos, de las cuales hemos digitalizado más del 60\%.

Palabras clave: humanidades digitales, bibliotecas digitales, catálogo online, relaciones de sucesos, historia del periodismo

Abstract: This paper reports on the work of cataloguing, digitizing and Internet broadcasting, which the research group on "Historia del periodismo en Andalucia" has developed during the last decade in Sevilla. We have registered in situ more than 1.200 news pamphlets, from whom we have digitized more than $60 \%$.

Keywords: digital humanities, digital libraries, online catalog, news pamphlets, history of journalism

\footnotetext{
${ }^{1}$ Este trabajo se inscribe en el proyecto de investigación y desarrollo tecnológico cofinanciado por el Ministerio de Ciencia e Innovación de España y el Fondo Europeo de Desarrollo Regional (FEDER): "Biblioteca Digital Siglo de Oro III" (BIDISO), código FFI2009-08113 (subprograma FILO).
} 


\section{Relaciones de sucesos: el primer periodismo de la Historia}

Las Relaciones de sucesos representan el primer periodismo de la Historia, teniendo en cuenta las semejanzas estéticas y funcionales existentes entre una relación de sucesos y un periódico. Se aprecian similitudes en el formato (noticias encabezadas por grandes titulares e imágenes que ilustran el acontecimiento), la redacción que pretende ser veraz mediante la presentación de datos (lugar y fecha del hecho), el carácter efímero del producto, la distribución callejera y la periodicidad. Asimismo, otro rasgo que nos permite considerar a las relaciones de sucesos como "forma primitiva del periodismo" (Redondo, 1995: 81) es su función eminentemente informativa ${ }^{2}$. Infantes lo subraya también al definir las relaciones de sucesos como "textos breves de tema histórico concreto con una intencionalidad de transmisión por medio del proceso editorial" (García de Enterría, 1996: 208). Ese periodismo, anterior al nacimiento de la prensa periódica e industrial, columpió sus intereses entre las noticias serias -la alta política, la guerra, las ceremonias cortesanas y religiosas- y las populares, esos casos espantosos tratados en muchas ocasiones con ribetes morbosos que sorprenden por su proximidad con el sensacionalismo de nuestros días. Relatos ocasionales de un acontecimiento con fines informativos, en su mayoría anónimos e impresos, las relaciones surgen en el siglo XV, con la invención de la imprenta, y perduran hasta el XX, pero se desarrollan sobre todo en el XVII y XVIII.

Sevilla fue un enclave especializado en la impresión y comercialización de este primer periodismo de la Historia. A lo largo de la primera Edad Moderna, la ciudad hispalense fue uno de los principales centros productores de relaciones de sucesos en España tanto en términos cuantitativos: hasta comienzos del siglo XVII acaparó la producción de, al menos, el $40 \%$ de este tipo de impresos en España; como en términos cualitativos: desde finales del siglo XVI albergó la producción periodística de innovadores maestros impresores como Rodrigo de Cabrera, Juan Serrano de Vargas y Juan Gómez de Blas (Espejo, 2008a).

Sin embargo, nuestro conocimiento acerca de ese primer periodismo de la Historia ha sido, durante mucho tiempo, aproximado o parcial, principalmente por la dificultad de acceder a los documentos originales, pero también por la propia naturaleza de estos documentos: impresos efímeros, baratos y de poca calidad material, considerados por muchos como géneros menores o infraliteratura. Urge, por tanto, la recuperación y la

\footnotetext{
${ }^{2}$ Cabe señalar que la naturaleza periodística de las relaciones de sucesos es un argumento aceptado por diversos autores en las últimas décadas, llegando incluso a calificar a la prensa popular -denominación en la que se agrupan las relaciones de sucesos junto con otros géneros editoriales efímeros (romances de ciego, oraciones, almanaques...) -como medios de comunicación de masas. Véase Sutherland (1991), Ettinghausen (1995), García de Enterría (1996), Núñez de Prado y Clavell (1997), Díaz G. Viana, (2000) o Chartier y Espejo (2012).
} 
revalorización de los fondos que contienen estos periódicos antiguos, fuentes esenciales para hacer la historia del periodismo.

En concreto, esta comunicación informa sobre las tareas de localización y catalogación, primero, y de digitalización y difusión en internet, después, que el grupo de investigación en "Historia del periodismo y las lecturas populares en Andalucía" ha venido realizando en la última década desde la Universidad de Sevilla, ocupándose de las relaciones de sucesos impresas durante la Edad Moderna en la ciudad hispalense. Se trata de una investigación que se ha llevado a cabo -y se sigue llevando a cabo- en el marco del proyecto "Biblioteca Digital Siglo de Oro" (BIDISO), dirigido por la profesora Sagrario López Poza (Universidade da Coruña) ${ }^{3}$.

La investigación realizada en Sevilla ha dado como resultado la catalogación de más de 1.200 impresos, de los cuales se han digitalizado más del 60\%, muchos de ellos desconocidos hasta la fecha y en su inmensa mayoría relaciones de sucesos, lo que confirma el extraordinario fondo de este tipo de documentos hemerográficos que aún se conserva en las bibliotecas sevillanas. Además, en la comunicación planteamos y desarrollamos una propuesta metodológica para la catalogación de prensa antigua, basada en una serie de descriptores bibliográficos y en la digitalización facsimilar de cientos de ejemplares.

El ingente corpus de relaciones de sucesos catalogadas y digitalizadas contiene obras desconocidas hasta el presente o de difícil localización, y resulta comparable en su valor con otras colecciones similares como las de la Biblioteca Nacional, la Hemeroteca Municipal de Madrid, la Real Academia de Historia o la Biblioteca Nacional de Cataluña. Estamos convencidos, por tanto, de que la comunidad académica que trabaja habitualmente con la prensa de la Edad Moderna saludará con entusiasmo este proyecto de investigación, puesta a disposición del público, además, a través de Internet en el Catálogo y biblioteca digital de Relaciones de Sucesos (siglos XVI-XVIII), obra del Grupo de Investigación sobre Relaciones de Sucesos (S.XVI-XVIII) de la Universidade da Coruña; y en la exposición virtual Relaciones de sucesos en la BUS: Antes de que existiera la prensa..., obra de la Biblioteca de la Universidad de Sevilla.

Los autores de esta comunicación pertenecen al grupo de investigación en "Historia del Periodismo y las Lecturas Populares en Andalucía", fundado en 2011 por la profesora Carmen Espejo Cala en el seno de la Facultad de Comunicación de la Universidad de Sevilla e integrado en el Plan Andaluz de Investigación, Desarrollo e

\footnotetext{
${ }^{3}$ El proyecto BIDISO se inscribe a su vez en el Seminario Interdisciplinar para el Estudio de la Literatura Aúrea Española (SIELAE), fundado también por la profesora López Poza en 1997 con el ánimo de fomentar el estudio de la literatura española de los Siglos de Oro desde perspectivas multidisciplinares. Uno de los cuatro equipos de investigación que integran el SIELAE se dedica a la catalogación, al estudio y a la digitalización de relaciones de sucesos españolas. El equipo ofrece el fruto de su trabajo en la página web http://www.bidiso.es/relaciones/.
} 
Innovación (PAIDI) ${ }^{4}$. Desde el grupo pretendemos promover, dirigir y coordinar trabajos de investigación académica que tienen por objeto el estudio del periodismo y la comunicación social en Andalucía, con especial interés en la dimensión social de las lecturas que el periodismo y otras formas de comunicación implican y en su confluencia con la denominada cultura popular ${ }^{5}$.

\section{La recuperación de una fuente histórica infravalorada}

Internet permite superar las barreras espacio-temporales que existen en las bibliotecas tradicionales y acceder a una cantidad de información inconmensurable. La pérdida del valor material, el auge de la instantaneidad y el deseo de compartir el conocimiento hacen cuestionarse la función de la biblioteca como guardiana de algunos objetos materiales con valor cultural. Según Díaz Noci (1999), la digitalización evita el deterioro o la desaparición y contribuye a la difusión de la cultura, permitiendo su acceso a estos objetos de estudio o fuentes de información.

La aparición de las bibliotecas virtuales permite realizar consultas independientemente de su ubicación geográfica. La digitalización de muchos de los documentos históricos permite acceder al pasado a partir de textos originales sin necesidad de desplazarse. Entre estos documentos se encuentran las relaciones de sucesos, ese formato informativo donde podemos situar el origen del periodismo. La posibilidad de acceder a reproducciones digitalizadas de relaciones originales a través de Internet abre nuevas líneas de investigación en la disciplina de la historia de la comunicación, facilita el trabajo de los estudiosos de esta materia y mejora su calidad docente.

A esta cuestión, López Poza, Pena Sueiro y Peñasco González han dedicado varios trabajos. Entre los títulos más destacados, se pueden señalar:

\footnotetext{
${ }^{4}$ Si bien el grupo de investigación es de reciente creación, el grupo de trabajo sobre relaciones de sucesos fue fundado mucho antes, en 1999, también por la profesora Carmen Espejo, en el seno de la Facultad de Comunicación de la Universidad de Sevilla. Más información sobre el grupo de investigación en el blog http://historiadelperiodismoenandalucia.wordpress.com/ y en su página de Facebook.

${ }^{5}$ La directora del grupo de investigación, Carmen Espejo, encabeza el proyecto "Los orígenes del periodismo en la Península Ibérica: catalogación, digitalización y difusión en Internet de gacetas, siglos XV-XVIII", de similares características al proyecto BIDISO sobre Relaciones de sucesos, pero centrado exclusivamente en otro tipo de formato periodístico, las Gacetas, y pendiente aún de financiación. La profesora Espejo participa también en el proyecto News Networks in Early Modern Europe junto a otros especialistas europeos. Financiado por el Leverhulme Trust, el proyecto pretende desvelar la condición pan-europea de las redes de noticias que cruzaban el continente desde el XVII en adelante.
} 
LÓPEZ POZA, S. Y PENA SUEIRO, N. (2000): Diseño de una base de datos para catalogación y estudio de Relaciones de sucesos.

LÓPEZ POZA, S. (2004): Catálogo y edición digital de relaciones de sucesos españolas accesible en Internet.

PEÑASCO GONZÁLEZ, S. (2009): Presentación de la nueva interfaz de consulta del Catálogo y biblioteca digital de relaciones de sucesos (siglos XVI-XVIII) del grupo de investigación sobre relaciones de sucesos (S. XVI-XVIII).

LÓPEZ POZA, S. (2011): Una base de datos en Internet con información bibliográfica y archivo digital de imágenes de Relaciones de sucesos españolas.

Urge así una renovación del concepto de biblioteca tradicional, donde el conocimiento no sólo se encuentre en lo material, sino también en lo inmaterial. En ese sentido Díaz Noci revisa la función de guardiana y cuidadora de los contenidos culturales que las bibliotecas han desempeñado tradicionalmente e insta a reducir las trabas de acceso a la reproducción de la información. "Nos toca decidir si poner puertas al campo del conocimiento, si encerramos el saber en cuatro paredes, si preservamos nuestras posesiones, o, si por el contrario, las ponemos a disposición de todo el mundo (...) Y esta es la función, creo yo, de las bibliotecas, que sirvan de apoyo al viaje" (Díaz Noci, 1999: 130-134).

De un valor incalculable para la investigación en torno a las relaciones de sucesos es la obra de Gonzalo García (2010): La biblioteca del relacionero: repertorios, catálogos y otras fuentes de información para la localización de las relaciones de sucesos (BIRESU). Se trata de una guía de consulta imprescindible donde se recopilan las fuentes de información disponibles en Internet sobre el tema: bibliotecas digitales, corpus textuales, exposiciones virtuales, portales temáticos o bases de datos.

Realizada esta breve pero indispensable reflexión panorámica acerca de lo que se ha producido recientemente en España sobre catalogación, digitalización y difusión de prensa antigua en Internet, debemos pasar a la formulación de los objetivos y las hipótesis que han movido nuestro trabajo. Debido a que la historia del periodismo de la Edad Moderna en España resulta insuficientemente conocida por los especialistas ${ }^{6}$, nuestro proyecto aspira a responder a esa necesidad, mediante el estudio de un corpus significativo de relaciones de sucesos conservadas en distintas bibliotecas sevillanas. Asimismo, las relaciones de sucesos han sido largamente olvidadas en las bibliotecas y archivos españoles, pese a que fueron pliegos informativos de una enorme popularidad en los siglos XVI-XVIII. La hipótesis científica que ha animado -y aún sigue animando- nuestra investigación es la relevancia de las relaciones de sucesos

\footnotetext{
${ }^{6}$ Pena argumenta que las relaciones de sucesos "han sido olvidadas durante mucho tiempo por los investigadores, deslumbrados, quizás, por las grandes obras literarias y artísticas que se crearon en esa época" (2001: 45).
} 
como imprescindibles fuentes hemerográficas e historiográficas que permiten conocer el contexto político, social y cultural de la época en la que se publican. Incluso, "relatan sucesos de los que no tenemos noticia a través de otros documentos" (Pena, 2001: 45). La Relación de sucesos, primer género del periodismo impreso, se consolida como producto tipográfico en Sevilla y otras grandes ciudades europeas en los primeros años del siglo XVII, como consecuencia del interés propagandístico y de la fiebre informativa que la Guerra de los Treinta Años (1618-1648) desata entre los poderes modernos y el público urbano respectivamente (Espejo 2008b).

Tradicionalmente, estos documentos sólo despertaban el interés de los historiadores cuando narraban de manera fidedigna algún acontecimiento relevante. En las últimas décadas, sin embargo, las relaciones no sólo han seguido siendo una fuente de información histórica cada vez más indispensable, sino que también se han convertido en un objeto de estudio per se y han generado estudios notables desde disciplinas como la Literatura, la Historia del Periodismo o la Sociología. No obstante, el investigador suele toparse con una serie de obstáculos que dificultan la localización, el acceso y el estudio de estas piezas: en primer lugar, las relaciones no suelen estar catalogadas en las bibliotecas, o lo están de manera deficiente, porque se han seguido criterios diversos para su clasificación; y, en segundo lugar, comparten a menudo encuadernación con otros pliegos sueltos en un volumen facticio o se hallan almacenadas en cajas de folletos.

Por tanto, el trabajo que hemos desarrollado en Sevilla, en el marco más amplio del proyecto BIDISO, tiene como objetivo principal la recuperación de una parte importante del patrimonio hemerográfico español, procediendo a la identificación y catalogación, primero, y a la digitalización y difusión en Internet, después, de las relaciones de sucesos impresas entre los siglos XVI y XVIII que se conservan en dos bibliotecas sevillanas: la Biblioteca Capitular y Colombina y la Biblioteca Universitaria. El propósito inicial que vertebra nuestra investigación radica en la necesidad de reescribir la historia del periodismo español de la Edad Moderna, aportando datos que permitan a los especialistas valorar la producción periodística desarrollada fundamentalmente en Sevilla, pero también en otras provincias andaluzas, procurando aumentar nuestro conocimiento del periodo y a la vez acompasar esta historia con la historia general del periodismo en Europa. Asimismo, con esta investigación pretendemos contribuir al esfuerzo que otras instituciones académicas españolas y europeas han realizado en las últimas décadas en torno a la creación de bibliotecas digitales de prensa antigua, y compensar así la inexistencia de recursos digitales específicos sobre el primer periodismo. 


\section{De los cajones olvidados a Internet: una propuesta de catalogación online y digitalización}

Una vez fijado el marco teórico desde el que se aborda la investigación, es pertinente describir la metodología utilizada, que se basa principalmente -y en este orden- en la localización, catalogación y digitalización de relaciones de sucesos publicadas durante la Edad Moderna. En estas tareas llevadas a cabo por el presente grupo de investigación en sesiones de trabajo semanales durante casi una década, también han colaborado -y colaboran- alumnos internos del departamento de Periodismo I de la Facultad de Comunicación de la Universidad de Sevilla, persiguiendo así el objetivo de formar en esta disciplina a futuros investigadores.

Respecto a la localización de los impresos analizados, esta labor se ha ido realizando en distintas bibliotecas hispalenses, que conservan un gran volumen de pliegos sueltos, los cuales precisan ser analizados, catalogados y digitalizados, para así garantizar su permanencia en el futuro. Cabe explicar que el registro de los documentos requiere un esfuerzo casi detectivesco, pues en muchas ocasiones se desconoce su paradero exacto. Esto es debido a que las relaciones de sucesos no se catalogaban como obras independientes, sino que se archivaban cosidas junto con otras composiciones de distinta naturaleza, formando parte de volúmenes misceláneos, o se dejaban sueltas en cajas con otros impresos. Es más, algunos ejemplares se han conservado al ser utilizados como relleno de encuadernaciones o mediante otros pragmáticos usos al margen de su primigenia función informativa o de entretenimiento; ya que una vez cumplido su cometido estos impresos carecían de valor, al ser considerados papeles viejos de la literatura de consumo (Moll, 1994).

Por tanto, el azar ha jugado un importante papel en la supervivencia de estas fuentes históricas y periodísticas, que han sido infravaloradas hasta hace apenas unas décadas, razón ésta por la que no solían incorporarse en los inventarios bibliográficos y pasaban a formar parte de lo que Infantes (1997) denomina la biblioteca ausente. Este generalizado desinterés por salvaguardar las relaciones de sucesos se debe fundamentalmente a su carácter efímero y a su bajo precio que no justificaba su tasación (Chartier, 1993). Ante esta problemática, nuestra búsqueda partía en muchas ocasiones de indicios o referencias que encontrábamos en los catálogos de algunos autores expertos en la materia como Agulló y Cobo (1966), Aguilar Piñal (1972), Domínguez Guzmán (1992)...

Una vez encontrado el documento y tras cerciorarnos de que cumple con los requisitos generales para ser considerado una Relación de sucesos (interés informativo del texto, breve extensión, título amplio, mala calidad en el papel, tipografía y grabados utilizados...) se produce la catalogación del mismo en una base de datos de acceso 
abierto, que describiremos a continuación. Si bien esto supone un avance, los investigadores actuales no sólo demandan conocer los datos de un documento, sino tener acceso directo al texto completo, mediante la digitalización facsimilar. Esta labor sí supone un notable avance bibliófilo y hemerográfico al convertir en formato digital impresos, cuya perdurabilidad estaba en riesgo, debido a su mal estado de conservación. La importancia de la digitalización reside también en que este proceso podrá permitir un progreso en los estudios de la prensa antigua, ya que la difícil localización y acceso a los originales provoca que "se repitan de manual en manual o de monografía en monografía ideas inexactas, conclusiones que solo tienen una validez parcial, incluso datos manifiestamente incorrectos" (Espejo, 2008c: 245). Una vez digitalizadas las relaciones mediante el uso de una cámara fotográfica digital y de un escáner portátil, las imágenes se envían a los responsables del proyecto BIDISO, con sede en la Universidade da Coruña, que se encargan de tratarlas y de introducirlas en la base de datos.

\subsection{Fuentes y su localización}

La principal fuente de información de esta investigación es nuestro propio objeto de estudio: las relaciones de sucesos. La selección del corpus se ajusta principalmente a dos únicos parámetros: el género del documento (relaciones de sucesos) y la fecha de publicación (siglos XVI-XVIII). De esta manera, se excluyen del repertorio otros impresos de gran difusión, tales como sermones, oraciones fúnebres, calendarios, comedias, sainetes, pasillos, etc., ya que nuestro interés fundamental está en los géneros periodísticos o pre-periodísticos. En otras palabras, analizamos sólo aquellos textos que tienen una función eminentemente informativa. Tal y como se muestra a continuación, la elección de las bibliotecas visitadas no es una cuestión aleatoria, sino que tomamos la decisión siendo conscientes de la riqueza bibliográfica y hemerográfica de estos archivos históricos de la capital hispalense, donde entre sus millares de volúmenes nos constaba la existencia de cientos de pliegos sueltos. La investigación se ha desarrollado en tres fases:

\section{Primera fase}

\section{Biblioteca Capitular y Colombina de Sevilla (2004-2007).}

Fundada apenas conquistada Sevilla (1248), dispone de un fondo de 60.000 volúmenes, en el que destacan importantes donaciones como la de Alfonso $\mathrm{X}$ el Sabio o la de Hernando Colón. Posee, entre otros documentos, más de 500 códices manuscritos y más de 1.000 ediciones incunables. Dado el interés científico que suscitan estos fondos, durante los años 2004 y 2007 se catalogaron y digitalizaron centenares de relaciones de sucesos, aunque estas tareas sólo se realizaron en la Biblioteca Capitular. Para la localización de estos documentos seguimos las referencias 
de algunos catálogos mencionados anteriormente e hicimos una pormenorizada búsqueda a través de las fichas manuales de esta biblioteca.

\section{Segunda fase}

\section{Biblioteca de la Universidad de Sevilla - Fondo Antiguo (2007- 2009).}

Está constituido por 917 volúmenes manuscritos, 330 incunables, 8.000 del siglo XVI y una amplísima colección de los siglos XVII y XVIII. Gracias a la inestimable ayuda del jefe de sección del Fondo Antiguo y Archivo Histórico de la BUS, Eduardo Peñalver Gómez, durante dos años analizamos una a uno todos los tomos de varios con impresos de la Edad Moderna. Tal fue el éxito obtenido por los hallazgos allí encontrados, que nuestro proyecto culminó con la publicación de la monografía Relaciones de sucesos en la BUS, antes de que existiera la prensa (2008) y la presentación de una Exposición Virtual de título homónimo. Además, las obras que digitalizamos forman parte del Portal de Fondos Digitalizados, que da acceso al texto completo de cerca de 3.000 impresos publicados entre los siglos XV y XIX.

\section{Tercera fase.}

\section{Biblioteca de la Universidad de Sevilla - Fondo Hazañas (2009- 2012).}

Joaquín Hazañas y La Rúa, bibliófilo, historiador y dos veces rector de la Hispalense, recopiló un notable volumen de relaciones de sucesos, canciones populares y romances vulgares ${ }^{7}$. Respecto a la localización, debido a la dispersión de estas obras, que están recopiladas sin orden aparente entre sus casi 300 cajas, el criterio de búsqueda ha sido topográfico, es decir, mirando caja por caja. En la actualidad seguimos catalogando y digitalizando los numerosos ejemplares de relaciones de sucesos hallados en este fondo.

\subsection{Descripción de la base de datos}

Como ya se ha mencionado en la introducción, el trabajo que venimos realizando en Sevilla desde hace una década, en el marco más amplio del proyecto BIDISO, ha servido para alimentar la base de datos bibliográfica Catálogo y Biblioteca Digital de

\footnotetext{
${ }^{7}$ La figura de Joaquín Hazañas y la Rúa (1862-1934) está íntimamente ligada a la Universidad de Sevilla, donde ejerció como Catedrático de Historia Universal (1898) y de Bibliología (1914), desarrollando una prolífica labor investigadora sobre distintos aspectos como la biografía del fundador de la Hispalense, Maese Rodrigo, o los orígenes de la imprenta sevillana.
} 
Relaciones de Sucesos (siglos XVI-XVIII) ${ }^{8}$. El grupo de trabajo ha empleado un programa de catalogación específico para relaciones de sucesos, diseñado y proporcionado por el grupo de investigación matriz en la Universidade da Coruña. El programa, muy intuitivo y de fácil manejo, permite insertar los datos de cada relación examinada de visu, directamente desde la biblioteca. Se trata de una base de datos más amplia que las convencionales, donde se incluyen datos bibliográficos fundamentales y datos complementarios extraídos de las relaciones como resultado de su análisis experto. Estos datos se agrupan en tres pantallas interactivas o conjuntos de información (Datos de la Obra, Datos de Edición y Datos de Ejemplar), que a su vez se desglosan en diferentes campos y descriptores ${ }^{9}$.

\section{Primera pantalla: Datos de la Obra.}

Esta entidad contiene información sobre los datos de cada relación concreta. Incluye, entre otros, los siguientes campos de información: Título (se transcribe respetando las grafías originales), Autor (quién escribe la relación), Lugar y Año del acontecimiento (no siempre coinciden con el lugar y el año de edición), Modalidad del discurso (si está escrita en prosa, en verso o si combina ambas modalidades), Tipología y subgénero, Epítetos (los adjetivos que acompañan en el título a la palabra "relación" o "carta").

- El lugar del acontecimiento, por ejemplo, aporta datos interesantes acerca de dónde provienen las noticias.

- Atendiendo a si las relaciones están escritas en prosa o en verso, podemos establecer diferencias temáticas e incluso cronológicas, así como las preferencias del público.

- La tipología permite clasificar cuáles tuvieron mayor éxito editorial o si había lugares especializados en imprimir un tipo determinado de relación.

\footnotetext{
${ }^{8}$ La base de datos se puede consultar en Internet: http://www.bidiso.es/RelacionesSucesosBusqueda/. Mediante este enlace se da acceso al catálogo, que contiene la descripción bibliográfica de más de 5.000 ediciones de relaciones de sucesos españolas, que se imprimieron de los siglos XVI al XVIII y se conservan en 175 bibliotecas de España, Portugal e Italia. También se ofrece, mediante la interfaz de consulta, información de otros aspectos de interés estudiados en las relaciones, así como digitalización completa de buena parte de los ejemplares.

${ }^{9}$ La descripción bibliográfica de la base de datos se ha hecho a partir de la Guía básica para inserción de datos en el Catálogo y Biblioteca Digital de Relaciones de Sucesos (siglos XVI-XVIII), elaborada por el grupo SIELAE (Universidade da Coruña) en mayo de 2007, y a partir del capítulo de S. López Poza y N. Pena (2000). Diseño de una base de datos para catalogación y estudio de relaciones de sucesos. En L. Díaz G. Viana (Coord.), Palabras para el pueblo. Vol. I. Aproximación general a la Literatura de Cordel (pp. 367-379). Madrid: Departamento de Antropología de España y América, Consejo Superior de Investigaciones Científicas.
} 


\begin{tabular}{|c|c|}
\hline Tipología & Subgénero \\
\hline Acontecimientos políticos y religiosos & $\begin{array}{l}\text { Acontecimientos militares } \\
\text { Acontecimientos políticos } \\
\text { Acontecimientos religiosos (no festivos) } \\
\text { Otros sucesos políticos y religiosos } \\
\text { Sátiras y críticas político-religiosas }\end{array}$ \\
\hline Ceremonias y festejos & $\begin{array}{l}\text { Beatificaciones y canonizaciones } \\
\text { Bodas } \\
\text { Consagraciones de iglesias } \\
\text { Entradas } \\
\text { Entradas públicas de eclesiásticos } \\
\text { Exequias } \\
\text { Exequias de eclesiásticos } \\
\text { Fiestas monárquicas } \\
\text { Fiestas por victorias político-militares } \\
\text { Fiestas religiosas } \\
\text { Nacimientos realeza, nobleza, etc. } \\
\text { Nombramientos de eclesiásticos } \\
\text { Otros festejos monárquicos } \\
\text { Otros festejos religiosos } \\
\text { Proclamaciones } \\
\text { Traslados de imágenes }\end{array}$ \\
\hline Viajes & $\begin{array}{l}\text { Descripciones geográficas } \\
\text { Exploración y conquista } \\
\text { Otros viajes } \\
\text { Viajes fantásticos }\end{array}$ \\
\hline Sucesos extraordinarios & $\begin{array}{l}\text { Milagros } \\
\text { Sucesos acaecidos a personas } \\
\text { Sucesos de la Naturaleza }\end{array}$ \\
\hline $\begin{array}{l}\text { Pronósticos } \\
\text { Otros temas }\end{array}$ & \\
\hline
\end{tabular}




\section{Segunda pantalla: Datos de Edición}

Esta entidad contiene información relativa a las ediciones de una relación ${ }^{10}$. Incluye, entre otros, los siguientes campos de información, incluidos muchos de ellos en los catálogos y repertorios convencionales que describen impresos antiguos: Editor e Impresor, Año y Lugar de edición (en este caso, se han modernizado las grafías), Tamaño (pliego, folio, 4ำ, 8ำ 16ㅇ), Número de páginas, Signatura tipográfica (se refiere a la marca -símbolos, letras- que ponía el impresor en la parte inferior de algunas páginas para facilitar el recuento de los pliegos y la encuadernación), Traductor, Portada (diferenciamos si es una portada convencional, si está orlada o grabada, o si sólo aparece un encabezamiento o una portadilla), Licencia, Privilegio y Aprobación, Idioma, Dedicatoria, Ilustración (la describimos de modo sencillo y escueto, por ejemplo, torreón, jarrón con flores, caballero y dama).

- La base de datos nos indica la existencia de editores o impresores especializados en negociar con este tipo de impresos.

- Combinando diferentes descriptores, como el impresor, el año de edición, el tamaño, la tipología o la portada, podemos obtener información relevante para la sociología de la edición.

- La dedicatoria nos aporta información acerca de quiénes eran las personalidades más influyentes de la época.

\section{Tercera pantalla: Datos de Ejemplar.}

Esta entidad contiene información sobre los ejemplares que se conservan de cada edición de una relación. Incluye los siguientes campos de información: Biblioteca, Signatura topográfica (números y/o letras que cada biblioteca asigna a sus ejemplares), Portada, Encuadernación, Ex Libris, Comentarios (si el ejemplar está o no completo, su estado de conservación), Investigador, Vista, Fuente bibliográfica, Texto transcrito, Páginas digitalizadas (en formato PDF, actualmente existen más de 1.600 ediciones digitalizadas en la base de datos), Referencias en Internet. La mayoría de estos datos contribuyen a desenmarañar la historia del ejemplar, así como a su posterior identificación y reconocimiento, pues a veces están encuadernados en tomos facticios y resultan difíciles de localizar si se ha perdido la portada o la primera hoja.

\footnotetext{
${ }^{10}$ Hemos trabajado con tres entidades que conviene distinguir muy bien: relación (es decir, una obra), edición y ejemplar. Una obra o relación puede haber tenido más de una edición, y a su vez, de cada edición podemos haber hallado y registrado varios ejemplares que estén en la misma o en distintas bibliotecas.
} 


\section{El valioso legado de la imprenta sevillana}

Una vez descritos los métodos de investigación y la base de datos que hemos utilizado para realizar la catalogación, pasamos a exponer los resultados cuantitativos y cualitativos de la investigación. Como miembros del grupo de investigación en "Historia del Periodismo y las Lecturas Populares en Andalucía" hemos participado activamente en las tareas que se han llevado a cabo hasta el momento, bajo la dirección y el magisterio de la profesora Carmen Espejo, identificando, catalogando y digitalizando una ingente cantidad de relaciones de sucesos.

Según el Catálogo y Biblioteca Digital de Relaciones de Sucesos (BDRS), desde Sevilla hemos registrado en la base de datos 1.243 ediciones, de las cuales 569 se conservan en la Biblioteca Capitular y Colombina y 674, en la Biblioteca Universitaria (Fondo Antiguo y Fondo Hazañas) ${ }^{11}$. Esto supone más del $22 \%$ del total de relaciones registradas (5.512 ediciones), es decir, una relación de cada 5 ha sido añadida a la BDRS por nuestro grupo de investigación.

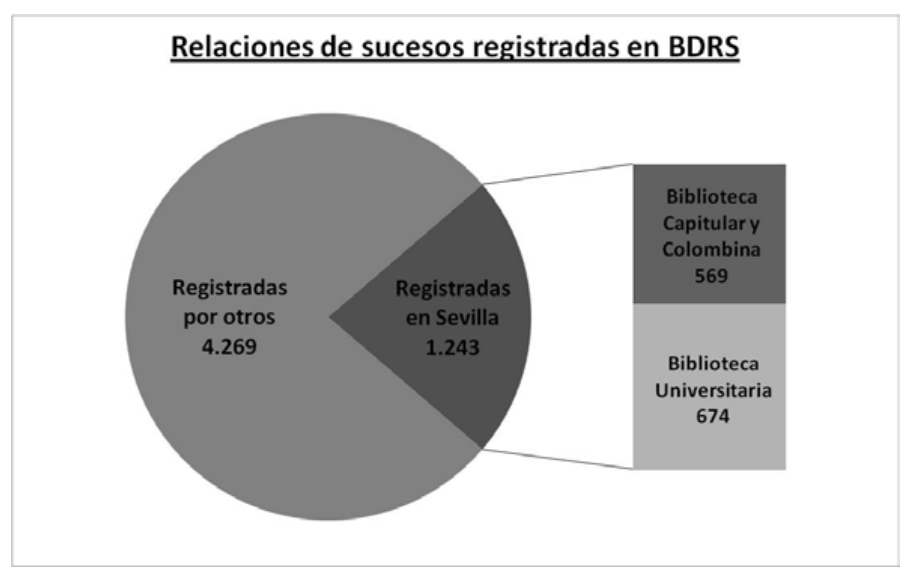

Asimismo, de esa cantidad total de 1.243 ediciones hemos digitalizado mediante el procedimiento descrito arriba 800 ediciones (más del 64\%), de las cuales 437 se conservan en la Biblioteca Capitular y Colombina y 363, en la Biblioteca Universitaria (Fondo Antiguo y Fondo Hazañas) ${ }^{12}$. Esto representa prácticamente la mitad (un $48,5 \%)$ del total de 1.649 ediciones digitalizadas que hay en la BDRS.

\footnotetext{
${ }^{11}$ Todas las consultas realizadas en el "Catálogo y Biblioteca Digital de Relaciones de Sucesos" (BDRS), de las cuales se han extraído los resultados expuestos en la comunicación, se realizaron con fecha de 4 de abril de 2012. Estos datos pueden variar con el paso del tiempo, puesto que se trata de una base de datos viva, en permanente crecimiento.

${ }^{12}$ En el caso del Fondo Antiguo de la Biblioteca Universitaria, no así en el Fondo Hazañas, en ocasiones la Relación de sucesos ya estaba digitalizada y sólo añadíamos el enlace a la digitalización de la BUS. En ocasiones éste es el único enlace a la digitalización y otras veces la relación se ofrece digitalizada también en otra biblioteca.
} 


\section{Relaciones de sucesos digitalizadas en BDRS}

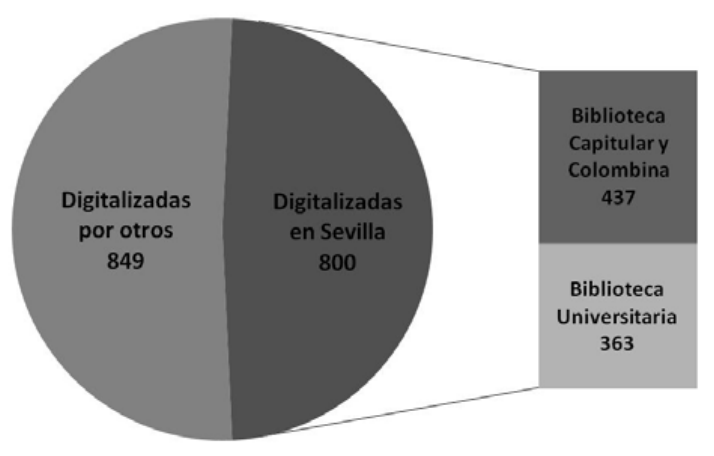

No obstante, más allá de las cifras globales, hemos decidido realizar una acotación del campo de trabajo para poder ofrecer un análisis provisional coherente sobre los resultados cuantitativos y cualitativos de la investigación. Así, atenderemos únicamente a las relaciones que presenten las siguientes características:

- Años de edición: entre 1500 y 1800, ambos años incluidos.

- Lugar de edición: Sevilla.

Siguiendo estos parámetros, hemos registrado 332 ediciones de relaciones de sucesos (198 digitalizadas), de las cuales 215 se conservan en la Biblioteca Capitular y Colombina (155 digitalizadas) y 117 en la Biblioteca Universitaria (43 digitalizadas). Esta cantidad nos parece suficiente para ofrecer una primera visión sobre el corpus que comprende la investigación.

Tomando como referencia la fecha de edición que indica la propia relación, 12 ediciones de las ya analizadas pertenecen al siglo XVI, 265 ediciones al siglo XVII y 55 al siglo XVIII. Las relaciones más antiguas del conjunto registrado datan de 1596 . Se trata de una serie de 8 ediciones monotemáticas (la guerra del Príncipe de Transilvania contra los turcos) publicadas sucesivamente a lo largo de ese año por el impresor sevillano Rodrigo de Cabrera, considerado un pionero del primer periodismo europeo (Espejo, 2008a) [véase Fig. 1]. 


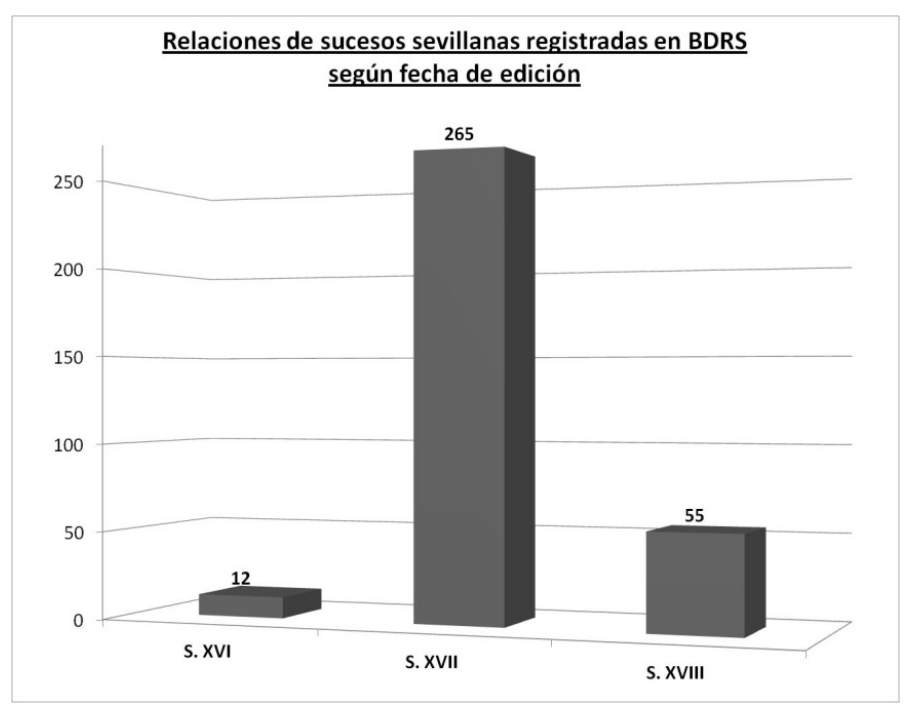

Por regla general, la producción de relaciones de sucesos se distribuye de manera uniforme a lo largo del período estudiado (1500-1800), si bien experimenta una alta concentración en determinados momentos que coinciden con importantes acontecimientos históricos. En el siglo XVII, por ejemplo, proliferan en Sevilla las relaciones sobre noticias religiosas, como la popular polémica de la Inmaculada Concepción de la Virgen (1615-1618); sobre noticias políticas, como la visita a Madrid del príncipe de Gales para negociar su matrimonio con la hermana de Felipe IV (1623); y sobre noticias militares, como la Guerra de los Treinta Años (a partir de 1622) y la posterior paz firmada en Westfalia (1648) o el levantamiento de los catalanes y el sitio de Barcelona (1651-1652) [véase Fig. 2]. En el siglo XVIII, por su parte, sobresalen dos grandes acontecimientos: la Guerra de Sucesión española, a comienzos de la centuria, y el terremoto de Lisboa de $1755^{13}$ [véase Fig. 3].

En cuanto a la autoría, la tónica dominante es la anonimia. De las 332 ediciones analizadas 274 son anónimas y sólo se menciona el autor en 58 casos, entre los que destaca Andrés de Almansa y Mendoza ${ }^{14}$ [véase Fig. 4]. Atendiendo a los lugares de referencia, sobresalen Sevilla (49 ediciones) y Madrid (28 ediciones).

\footnotetext{
${ }^{13}$ Véase el informe sobre los fondos de relaciones de sucesos conservadas en la Biblioteca Capitular y Colombina, obra de Carlota Fernández Travieso (2006). La colección de relaciones de sucesos de la biblioteca capitular de Sevilla. En López Poza, S. (Ed.), Las noticias en los siglos de la imprenta manual (pp. 233-255). A Coruña: SIELAE.

${ }^{14}$ Andrés Almansa y Mendoza es el periodista sevillano más conocido del primer tercio del siglo XVII. Vinculado a los más importantes personajes de la política española, introduce el periodismo en Madrid. La mayoría de sus relaciones, redactadas en forma de carta con un estilo típicamente reporteril, describen acontecimientos importantes de la Corte, como la muerte de Felipe III o la visita del príncipe de Gales, pero también incluyen asuntos del extranjero, corridas de toros y notas sobre la familia real.
} 


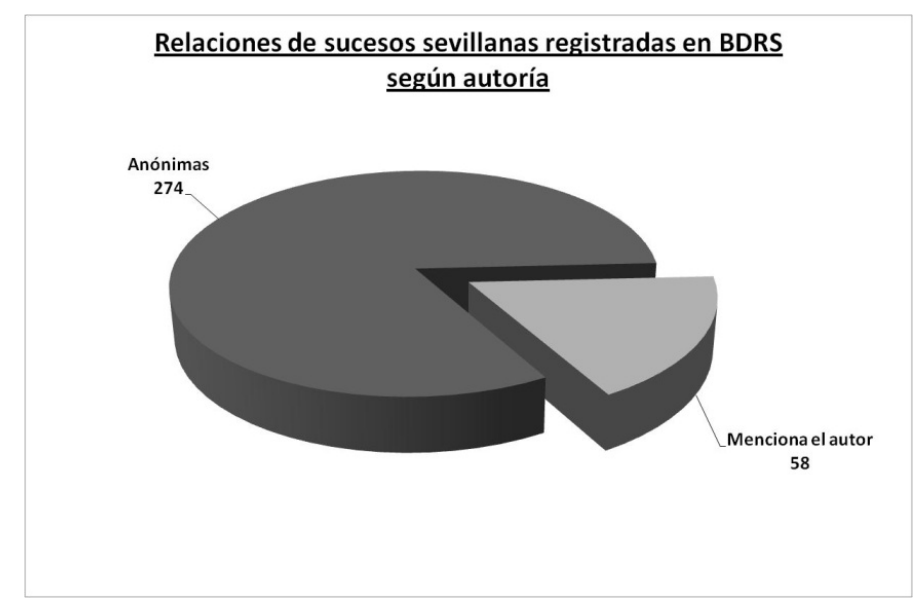

En el siglo XVII sobresale el volumen de la producción del impresor sevillano Juan Gómez de Blas, con 111 ediciones. Editor de la más destacada de las gacetas provinciales, réplica no obstante de la madrileña, goza además de reconocimiento oficial: en 1657, se convierte en el primer impresor sevillano que obtiene el privilegio de "Impresor Mayor" de la ciudad [véase Fig. 5]. A Juan Gómez de Blas le siguen Francisco de Lira con 32 relaciones, quien dedica especial atención a los avisos procedentes de Flandes, y Juan Serrano de Vargas con 22, producción de su etapa inicial sevillana (1617-1625) que le proclama como un verdadero especialista en la edición de relaciones de sucesos ${ }^{15}$ [véase Fig. 6]. En los años finales del siglo XVI destaca el impresor Rodrigo de Cabrera, con 12 relaciones.

En cuanto a los temas de los que se informa en las relaciones, hemos empleado la tipología propuesta por el grupo de investigación SIELAE para su "Catálogo y Biblioteca Digital de Relaciones de Sucesos (siglos XVI-XVIII)", descrita arriba. Así, hemos encontrado que la gran mayoría de las relaciones (206 ediciones) forman parte del apartado "Acontecimientos políticos y religiosos". Dentro de este apartado proliferan las relaciones sobre "Acontecimientos militares" (127 ediciones) [véase Fig. 7]. El resto de piezas de esta tipología versa sobre "Acontecimientos religiosos no festivos" (25 ediciones) y "Acontecimientos políticos" (23 ediciones). El segundo apartado en número de relaciones registradas es el de "Ceremonias y festejos" (79 ediciones). En esta tipología predominan las ceremonias de carácter político con 45 relaciones, referentes fundamentalmente a bodas, entradas y nacimientos entre la familia real o la nobleza, sobre las ceremonias de carácter religioso (34). Dentro del apartado "Sucesos extraordinarios" tenemos 28 relaciones, en su mayoría sobre "Sucesos de la naturaleza" (18 ediciones), como consecuencia de la producción informativa que generó el terremoto de 1755 . El resto de piezas de esta tipología versa sobre

\footnotetext{
${ }^{15}$ Sobre los inicios del periodismo en Sevilla y la producción de estos impresores, véase C. Espejo (2008). El mercado de noticias en Sevilla: de las Relaciones a las Gacetas. En C. Espejo, E. Peñalver y M. Rodríguez (Coords.), Relaciones de Sucesos en la BUS, antes de que existiera la prensa... (pp. 38-49). Sevilla: Universidad de Sevilla, Biblioteca, Departamento de Periodismo I.
} 
"Milagros" (9 ediciones) y "Sucesos acaecidos a personas" (1 edición) [véase Fig. 8]. Finalmente, sólo hemos registrado 2 relaciones en el apartado "Viajes" y 17 en "Otros temas".

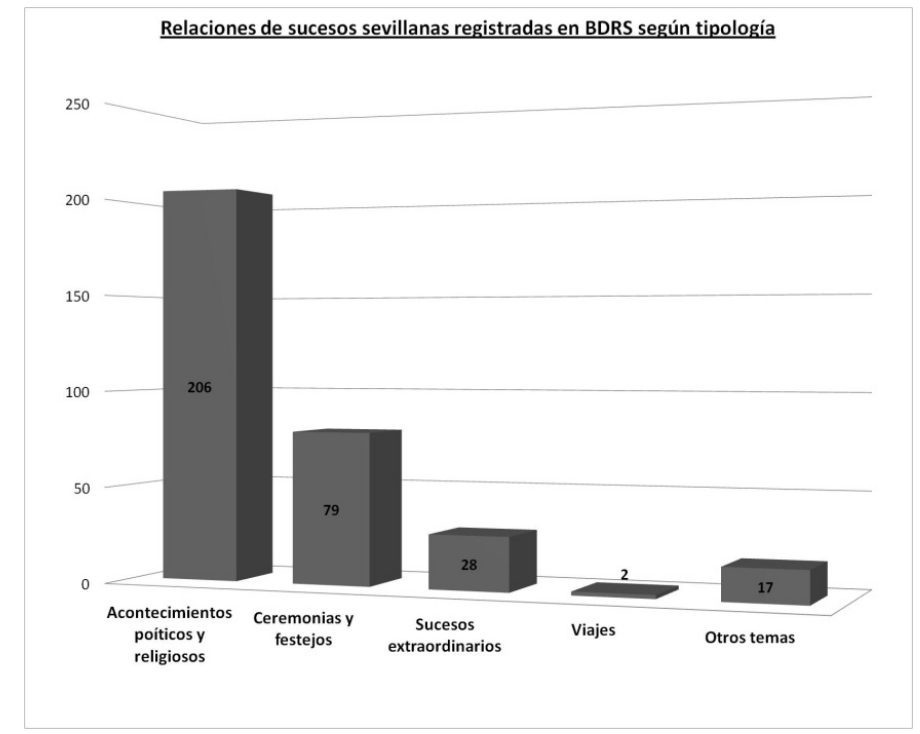

La gran mayoría de las relaciones poseen un título largo que resume su contenido. Es habitual que la edición venga encabezada por la palabra "relación", que aparece hasta en 197 ocasiones al inicio del título. En 47 casos el discurso se inicia con la palabra "carta" o sus variantes (copia o capítulo de una carta). El término "gazeta" aparece en 20 ocasiones y "noticia" en 22 casos. El sustantivo que encabeza el título suele ir acompañado de calificativos o epítetos que enfatizan la brevedad y concisión de la noticia (breve, sumaria, sucinta, particular, puntual), su veracidad (verdadera), su novedad (nueva) o su interés (singular, grandiosa, extraordinaria, curiosa, prodigiosa, maravillosa).

En cuanto a la modalidad del discurso, las relaciones escritas en prosa predominan abrumadoramente (226 ediciones) sobre las escritas sólo en verso (22 ediciones) y las que combinan la prosa y el verso (12 ediciones). Sin embargo, se observa en el siglo XVIII un incremento de las relaciones en verso. En el siglo XVII 185 piezas están escritas en prosa y tan sólo 6 están en verso, mientras que sólo 5 contienen prosa y verso. En el siglo XVIII, si bien sigue habiendo más relaciones en prosa (29), hay 15 en verso y 8 que contienen prosa y verso.

Más allá de los resultados alcanzados, a lo largo de la investigación hemos tenido que afrontar algunas dificultades que de un modo $u$ otro han limitado o ralentizado un poco las tareas realizadas en nuestro proyecto, aunque no por ello se ha disminuido nuestro interés por cumplir los objetivos propuestos.

- Localización de impresos: A pesar de la publicación de diversos estudios y repertorios de relaciones de sucesos, la localización de estas obras aún continúa 
siendo una labor que requiere mucha dedicación, al tener que hacer búsquedas topográficas en cajas de varios o en obras misceláneas de las bibliotecas visitadas ${ }^{16}$.

- Definición del concepto: La identificación de estos impresos en ocasiones se convierte en una ardua tarea debido a la compleja definición del término Relación de sucesos, un concepto tan polivalente que a veces desconcierta incluso a los autores más eruditos, pues Infantes (1996: 203-204) apunta que "existir, existen (y a miles); otra cosa es saber qué son y los límites de sus reconocimientos (...) además, estoy ciertamente cansado de ver (y hasta de leer) relaciones y no saber en ocasiones qué veo (o qué leo) con cierta seguridad".

- Selección del ejemplar: Frecuentemente en estos impresos se omite información necesaria para su análisis (autoría, fecha del acontecimiento, pie de imprenta), estas carencias no sólo dificultan la catalogación del ejemplar, sino que provocan inconvenientes a la hora de seleccionar el documento, ya que no podemos saber con seguridad si fue publicado dentro de los márgenes temporales fijados ${ }^{17}$. Es entonces cuando recurrimos a otros datos que nos aporten pistas sobre su fecha de publicación, ya sea por la época en la que desarrollaron su producción el impresor o el autor, el año en el que ocurrió el suceso relatado (si aparece explícitamente o está documentado en otras fuentes históricas) o la tipografía utilizada.

- Catalogación según la modalidad: La hibridez temática, propia de los productos de la cultura popular, también complica la clasificación de las relaciones de sucesos según las opciones de modalidad, tipología y subgénero propuestas en la BDRS: acontecimientos políticos y religiosos, relaciones de viajes, sucesos extraordinarios... De ahí que hayamos optado por elegir la temática dominante en la obra, aunque pueda abarcar otras categorías.

- Fragilidad del documento: El deterioro que sufren muchos de los ejemplares estudiados (falta de páginas, roturas, hongos...) frena en muchas ocasiones el ritmo de catalogación y digitalización de las relaciones de sucesos, porque la fragilidad del documento nos obliga a tratarlo con sumo cuidado $y$, además, no nos permite conocer la totalidad del texto ${ }^{18}$.

\footnotetext{
${ }^{16}$ López (1997: 295) insiste en la necesidad de elaborar repertorios bibliográficos de todos estas obras, a pesar de los "no pocos obstáculos" existentes en esta tarea, como la falta de catalogación de los pliegos sueltos en muchas bibliotecas.

${ }^{17}$ Es habitual encontrar relaciones de sucesos donde no se ofrecen indicaciones sobre el autor y el impresor, esto se debe a que la anonimia era una estrategia que permitía escapar de la censura. Cabe recordar que desde sus orígenes este género ha sufrido el reiterado control gubernamental, que puso trabas a la producción y distribución de estas obras (De los Reyes, 2000).

${ }^{18}$ El mal estado de conservación de este tipo de impresos no es un problema que se produzca sólo en los fondos explorados, sino un obstáculo extensible a todas las bibliotecas y archivos. De hecho, López y Pena (2000) subrayan esta traba como uno de los principales inconvenientes que tienen que superar los investigadores de Relaciones de sucesos.
} 


\section{Conclusiones}

Tal y como se ha descrito arriba, nuestra investigación acerca de las relaciones de sucesos ha comprendido una serie de tareas que se han desarrollado siempre en un mismo orden cronológico: una primera fase de localización e identificación, una segunda fase de descripción y catalogación, y una tercera y última fase de digitalización y difusión en Internet. Este trabajo de investigación nos ha conducido a su vez a confirmar nuestras hipótesis de partida (el desconocimiento que existe aún sobre la historia del periodismo durante la Edad Moderna y la importancia de Sevilla como foco productor de relaciones de sucesos) y a cumplir con el objetivo principal que nos planteábamos al comienzo de la comunicación (la recuperación de una parte importante del patrimonio hemerográfico español). Si bien aún no podemos considerar definitivos los datos, ya podemos establecer una descripción general en torno a la producción de relaciones de sucesos en Sevilla, a partir del ingente corpus de documentos que hemos catalogado y digitalizado hasta ahora.

- Año de edición: Una abrumadora mayoría de las relaciones de sucesos impresas en Sevilla (80\%) se publicaron durante el siglo XVII, lo que contrasta con la escasa producción conservada del siglo XVI $(3,5 \%)$ o con la modesta producción dieciochesca (16,5\%). Esto confirma, por un lado, la consolidación que las relaciones de sucesos, en tanto que género informativo, experimentan durante el siglo XVII; y, por otro, la consideración de Sevilla, a lo largo de la primera Edad Moderna, como un taller en el que se ensayaba con las primeras formulaciones impresas del periodismo.

- Autoría: Predomina la anonimia, pues 8 de cada 10 relaciones no indican quién es su autor, lo que nos muestra la escasa importancia del escritor en comparación con la figura omnipresente del impresor, responsable jurídico de la obra.

- Lugar de edición: Sólo una cuarta parte de las relaciones de sucesos conservadas en bibliotecas sevillanas, cerca del $27 \%$, se imprimieron en Sevilla, lo cual nos indica que era un foco activo de consumo -más que de producción- de noticias, como consecuencia de su intensa actividad comercial y cultural.

- Impresores: Hasta un tercio de las relaciones de sucesos impresas en Sevilla durante la Edad Moderna fueron obra de Juan Gómez de Blas, lo que confirma su prolífica actividad periodística y justifica su reconocimiento oficial como primer "Impresor Mayor" de la ciudad.

- Lugares de referencia: Una lectura más detenida de esta variable nos indica que sólo el $15 \%$ de las relaciones impresas en Sevilla informaban sobre acontecimientos ocurridos en la misma ciudad, lo que muestra el escaso interés informativo que entonces despertaban las noticias locales.

- Tipología: La temática más tratada son los "Acontecimientos políticos y religiosos", representando más del $62 \%$ de las relaciones analizadas, entre las 
cuales proliferan las relaciones sobre "Acontecimientos militares" ( 6 ediciones de cada 10). Esto confirma la fiebre informativa que desataron conflictos bélicos como la Guerra de los Treinta Años, el sitio de Barcelona o la Guerra de Sucesión. Destaca también las relaciones de "Ceremonias y festejos" (cerca del $24 \%$ del total), entre las que sobresalen las ceremonias de carácter religioso (4 de cada 10 ediciones), que en su mayoría derivan del tema de la Inmaculada.

- Título: la palabra "relación" aparece encabezando el título de las ediciones en cerca del $60 \%$ de los casos, lo que confirma la identificación y consolidación de las relaciones de sucesos como un género editorial, como un formato informativo independiente. Además, observamos cómo desde los inicios del periodismo se enfatizan también en el título los rasgos esenciales, clásicos, de la información periodística, tales como la brevedad, la concisión, la veracidad, la novedad o el interés de la noticia.

- Modalidad del discurso: Mientras que en el siglo XVII la proporción entre las relaciones escritas en prosa y las escritas en verso (y prosa) es de 94 a 6 , en el siglo XVIII la proporción es de 56 a 44. Se confirma la tesis de Fernández (2006), según la cual el avance del verso frente a la prosa en el siglo XVIII obedece a la propia evolución de la Relación de sucesos, que se redefine como género ante la consolidación de las gacetas y los diarios, adoptando una nueva forma: el verso.

Aún queda trabajo por hacer en cuanto a la catalogación, digitalización y difusión en Internet de relaciones de sucesos conservadas en las bibliotecas sevillanas, prueba de ello es que actualmente seguimos añadiendo a la BDRS ediciones procedentes del Fondo Hazañas de la Biblioteca de la Universidad de Sevilla. Estas páginas, de hecho, sólo constituyen una mirada provisional sobre la colección de relaciones impresas en Sevilla durante la Edad Moderna, si bien nos permiten avanzar en el esclarecimiento de lo que podemos esperar de un análisis completo en el futuro. Finalmente, confiamos en que el resultado de nuestro esfuerzo sirva, por una parte, de acicate a futuros investigadores para que sigan profundizando en el conocimiento de unos fondos, a partir de ahora, más cercanos y accesibles; y, por otra, contribuya a poner en valor la relevancia del primer periodismo de la Historia, así como la excepcionalidad de los fondos conservados en la Biblioteca Capitular y Colombina y en la Biblioteca Universitaria de Sevilla.

\section{Bibliografía}

AGUILAR PIÑAL, F. (1972). Romancero popular del siglo XVIII. Madrid: CSIC.

AGULLÓ Y COBO, M. (1966). Relaciones de sucesos. Madrid: CSIC. 
BAENA, F. (2008). Entre quality papers y prensa amarilla: los "casos espantosos". En C. Espejo, E. Peñalver y M. Rodríguez (Coords.), Relaciones de Sucesos en la BUS, antes de que existiera la prensa... (pp. 82-94). Sevilla: Universidad de Sevilla, Biblioteca, Departamento de Periodismo I.

BIBLIOTECA DE LA UNIVERSIDAD DE SEVILLA (2011). Memoria Anual de la BUS 2010. Sevilla: Biblioteca de la Universidad de Sevilla.

BRISABOA, R. (1999). Interfaz de consulta a una base de datos de Relaciones de sucesos vía Internet. En S. López Poza y N. Pena Sueiro (Eds.), La fiesta. Actas del II Seminario de Relaciones de Sucesos (A Coruña, 13-15 de julio de 1998) (pp. 2912). Ferrol: Sociedad de Cultura Valle Inclán.

CASAS DELGADO, I. (2012). Romances con acento andaluz. El éxito de la prensa popular (1750-1850). Sevilla: Fundación Centro de Estudios Andaluces.

CHARTIER, R. (1993). Libros, lecturas y lectores en la Edad Moderna. Madrid: Alianza Editorial.

CHARTIER, R. Y ESPEJO, C. (Eds.) (2012). La aparición del periodismo en Europa: comunicación y propaganda en el Barroco. Madrid: Marcial Pons.

DÍAZ G. VIANA, L. (Coord.). (2000). Palabras para el pueblo. Vol. I, Aproximación general a la literatura de cordel. Madrid: Consejo Superior de Investigaciones Científicas, Departamento de Antropología de España y América.

DÍAZ NOCI, J. (1999). La biblioteca virtual, ¿de la biblioteca de Alejandría a la biblioteca de Babel? Producción, transmisión y almacenamiento de la información en la era digital. Bidebarrieta. Anuario de Humanidades y Ciencias Sociales de Bilbao, 5, 123-136.

DOMíNGUEZ GUZMÁN, A. (1992). La imprenta en Sevilla en el siglo XVII, Sevilla.

EIROA SAN FRANCISCO, M. (2008). Estudiando el pasado con la tecnología del futuro. Nuevas perspectivas para la Historia del Periodismo. Telos: Cuadernos de comunicación e innovación, 77, 134-138.

ESPEJO, C. (2008a). Los inicios del periodismo en Sevilla: desde las cartas de aviso a las relaciones de sucesos. En C. Espejo, E. Peñalver y M. Rodríguez (Coords.), Relaciones de Sucesos en la BUS, antes de que existiera la prensa... (pp. 26-37). Sevilla: Universidad de Sevilla, Biblioteca, Departamento de Periodismo I.

-(2008b). El mercado de noticias en Sevilla: de las Relaciones a las Gacetas. En C. Espejo, E. Peñalver y M. Rodríguez (Coords.), Relaciones de Sucesos en la BUS, antes de que existiera la prensa... (pp. 38-49). Sevilla: Universidad de Sevilla, Biblioteca, Departamento de Periodismo I. 
ESPEJO CALA, C. (2008c). El impresor sevillano Juan Gómez de Blas y los orígenes de la prensa periódica. La Gazeta Nueva de Sevilla (1661-1667). Zer Revista de Estudios de la Comunicación, 25, 243-267.

ESPEjO CALA, C., PEÑAlVER GÓMEZ, E., ROdRíGUEZ BRITO M.D. (Coords.) (2008). Relaciones de sucesos en la BUS, antes de que existiera la prensa. Sevilla: Universidad de Sevilla, Biblioteca, Departamento de Periodismo I.

ETTINGHAUSEN, H. (1995). Política y prensa "popular" en la España del siglo XVII. Anthropos: Boletín de información y documentación, № 166-1667, pp. 86-90.

FERNÁNDEZ TRAVIESO, C. (2006). La colección de relaciones de sucesos de la biblioteca capitular de Sevilla. En López Poza, S. (Ed.), Las noticias en los siglos de la imprenta manual (pp. 233-255). A Coruña: SIELAE.

GARCÍA DE ENTERRÍA, M. C. ET ALII (Eds.) (1996). Las relaciones de sucesos en España (1500-1750). Actas del primer coloquio internacional (Alcalá de Henares, 8, 9 y 10 de junio de 1995). Alcalá de Henares: Servicio de Publicaciones de la Universidad de Alcalá y Publications de la Sorbonne.

GONZÁLEZ GARCÍA, C. (2010). La biblioteca del relacionero: repertorios, catálogos y otras fuentes de información para la localización de las relaciones de sucesos (BIRESU). A Coruña: SIELAE y Sociedad de Cultura Valle Inclán.

HAZAÑAS Y LA RÚA, J. (2010). La imprenta en Sevilla. Sevilla, Diputación de Sevilla, Ayuntamiento de Sevilla, ICAS.

INFANTES, V. (1995). La poesía de cordel. Anthropos: Boletín de información y documentación, № 166-1667, pp. 43-46.

- (1997). Las ausencias en los inventarios de libros y bibliotecas. Bulletin Hispanique, Tomo 99, no 1, 281-292.

LÓPEZ POZA, S. Y PENA, N. (2000). Diseño de una base de datos para catalogación y estudio de relaciones de sucesos. En L. Díaz G. Viana (Coord.), Palabras para el pueblo. Vol. I. Aproximación general a la Literatura de Cordel (pp. 367-379). Madrid: Departamento de Antropología de España y América, Consejo Superior de Investigaciones Científicas.

LÓPEZ POZA, S. (2003). Una base de datos en Internet con información bibliográfica y archivo digital de imágenes de Relaciones de sucesos españolas. En A. Paba,y G. Andrés Renales (Coord.), Encuentro de civilizaciones (1500-1750). Informar, narrar, celebrar. Actas del Tercer Coloquio Internacional sobre Relaciones de Sucesos (Universidad Degli Studi di Cagliari, 5-8 de septiembre de 2001) (pp. 2132). Alcalá de Henares: Universidad de Alcalá, SIERS. 
- (2004). Catálogo y edición digital de relaciones de sucesos españolas accesible en Intenet. En A. Miguel Alonso, G. Carrizo Sainero e I. García-Monge (Eds.), Trabajos de la VIII reunión de la Asociación Española de Bibliografía (pp. 93-102). Madrid: Asociación Española de Bibliografía y Biblioteca Nacional.

MOLL, J. (1994). De la imprenta al lector. Estudios sobre el libro español de los siglos XVI al XVIII. Madrid: Arco Libros.

NÚÑEZ DE PRADO Y CLAVELL, S. M. (1997). Los antecedentes del periódico de masas: ocasionales, canards y almanaques. Madrid: Universidad Europea de MadridCEES.

PENA SUEIRO, N. (1996). Una propuesta de base de datos relacionales para catalogar relaciones. En H. Ettinghausen, V. Infantes de Miguel, A. Redondo y M.C García de Enterría (Coord.), Las relaciones de sucesos en España (1500-1750). Actas del primer coloquio internacional (Universidad de Alcalá de Henares, 8,9 y 10 de junio de 1995) (pp.275-286). Alcalá de Henares: Universidad de Alcalá.

- (1999). Un catálogo informatizado y biblioteca digital de Relaciones de sucesos (s. XVI-XVIII): Problemas y soluciones. En III Xornadas de Arquivos. Bibliotecas e Museos de Galicia (Ferrol, 23-25 de Setembro de 1999) (pp. 529538). Santiago de Compostela: Xunta de Galicia.

- (2001). Estado de la cuestión sobre el estudio de Relaciones de sucesos. Pliegos de Bibliofilia, 13, 43-66.

PEÑASCO GONZÁLEZ, S. M. (1999). El Catálogo y Biblioteca Digital de Relaciones de Sucesos (siglos XVI-XVIII): problemas y modificaciones. En III Xornadas de Arquivos, Bibliotecas, Centros de documentación e Museos de Galicia, as novas tecnoloxías ó servicio do usuario (Un. da Coruňa, Ferrol, 23-25 setembro 1999) (pp. 529-537). Xunta de Galicia.

- (2009). Presentación de la nueva interfaz de consulta del Catálogo y biblioteca digital de relaciones de sucesos (siglos XVI-XVIII) del grupo de investigación sobre relaciones de sucesos (S. XVI-XVIII). En P. Bégrand (Ed.), Representaciones de la alteridad, ideológica, religiosa, humana y espacial en las relaciones de sucesos, publicadas en España, Italia y Francia en los siglos XVI-XVIII. Actas del V Congreso Internacional SIERS, (6-8 de septiembre de 2007) (pp. 93-99). Besançon: Université de Franché-Comté.

REDONDO, A. (1995). Características del "periodismo popular" en el Siglo de Oro. Anthropos: Boletín de información y documentación, № 166-1667, pp. 80-85.

SANTOS FERNÁNDEZ, C. (2000). Contribución al Catalogo de Relaciones de Sucesos en bibliotecas de la provincia de A Coruña. Cuadernos de Estudios Gallegos, Tomo XLVII, Fascículo 112, 401-439. 
SUTHERLAND, M. (1991). Mass culture in the Age of the Enlightenment: the blindman's ballads of Eighteenth-century Spain. New York: Peter Lang.

Webs consultadas (todas con acceso el 4/4/2012):

http://www.icolombina.es/colombina/index.htm

http://bib.us.es/relacionesdesucesos/

http://fondosdigitales.us.es/fondos/busqueda avanzada/

http://www.bidiso.es/boresu/Bibliografia.html

http://www.bidiso.es/boresu/boletines.html

http://prensahistorica.mcu.es 


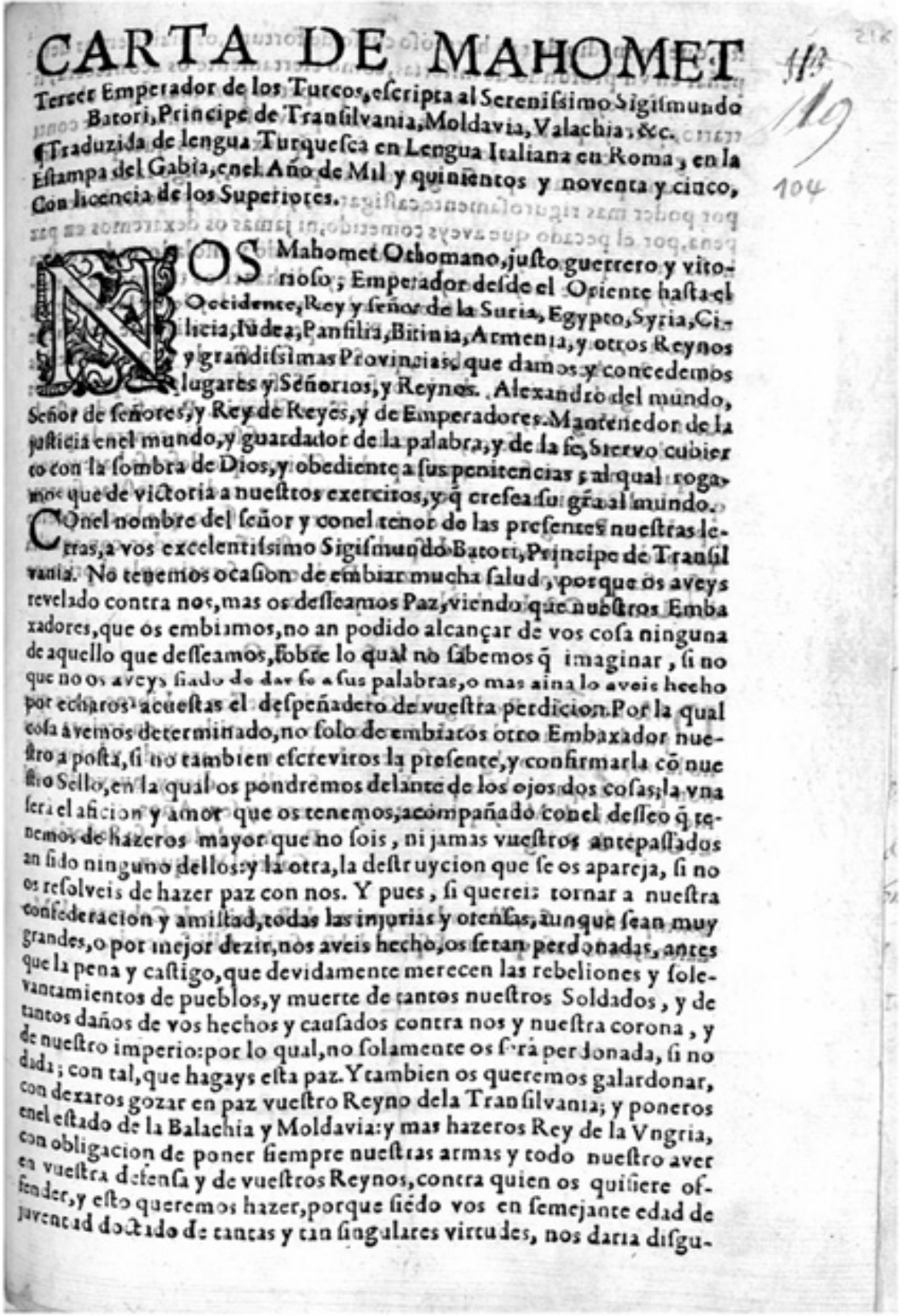

Fig. 1 


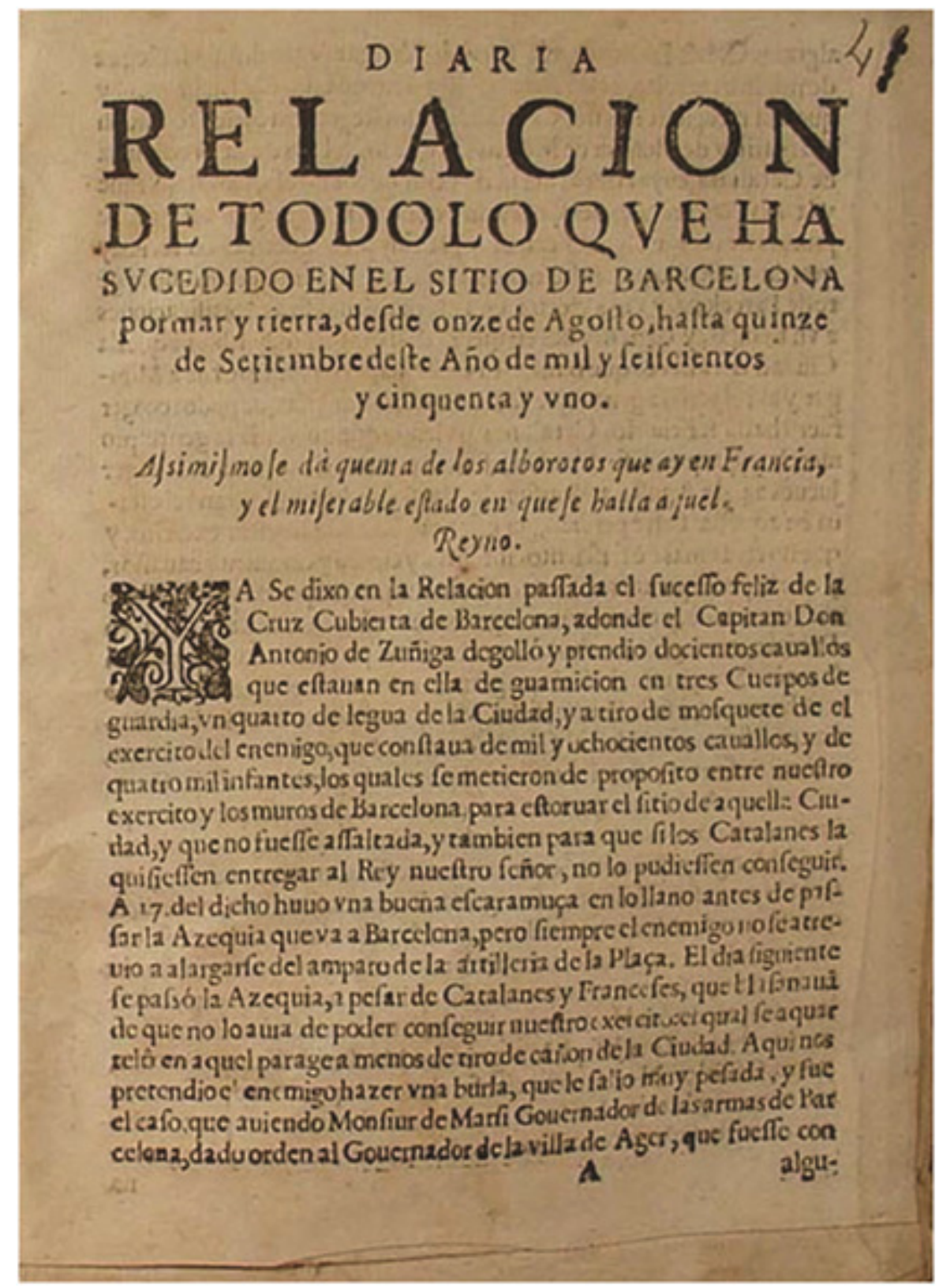

Fig. 2 


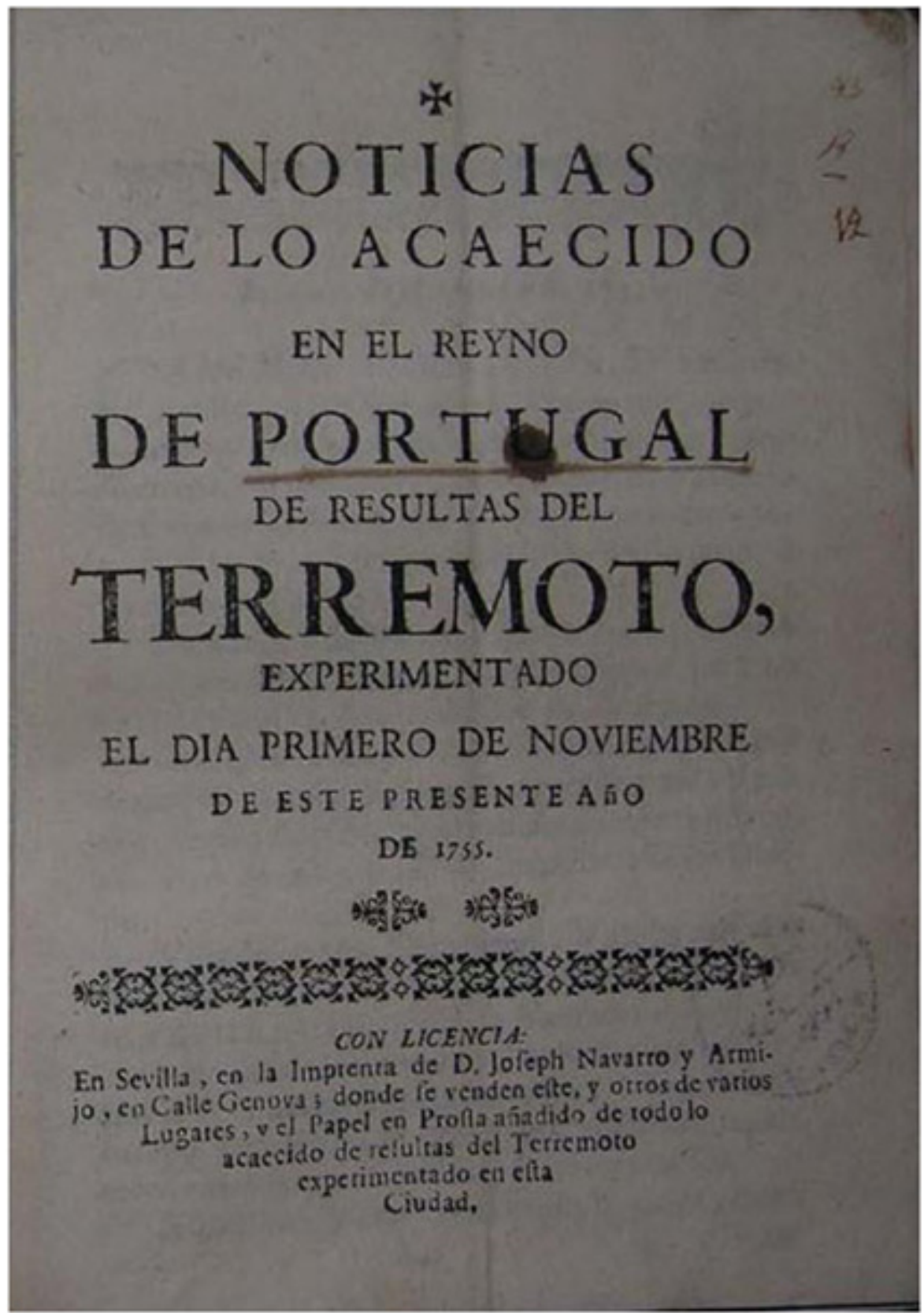

Fig. 3 


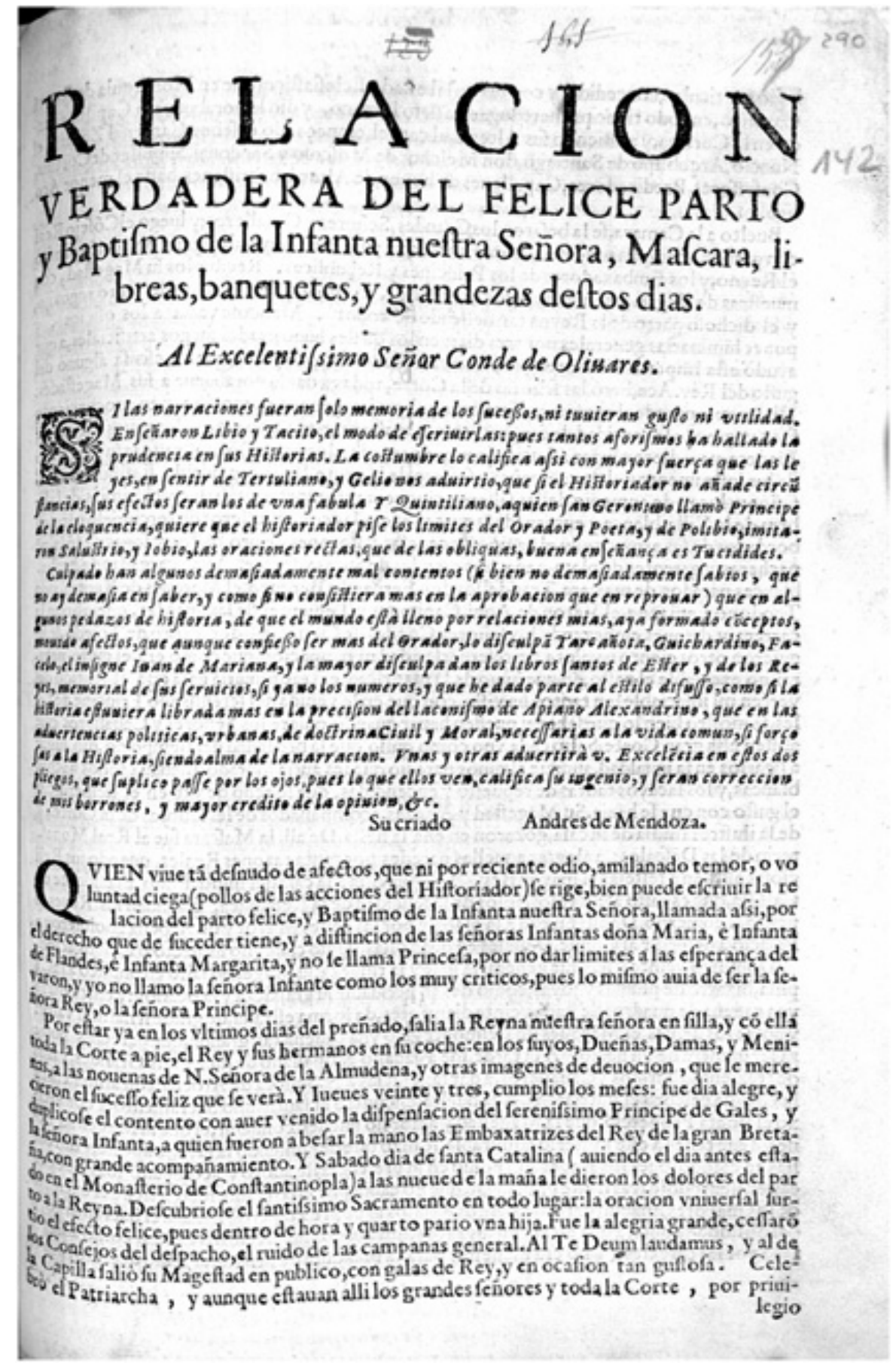




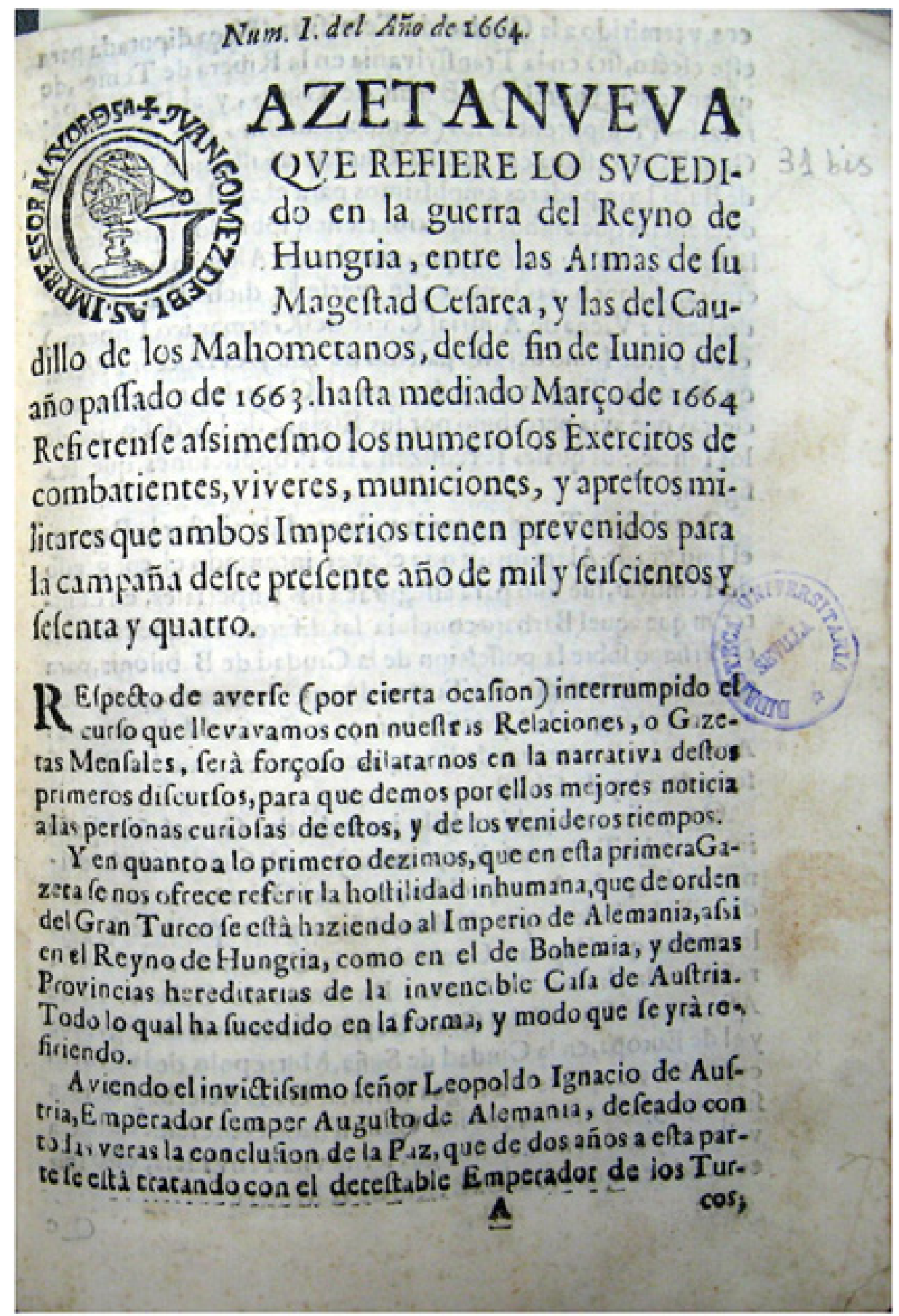

Fig. 5 


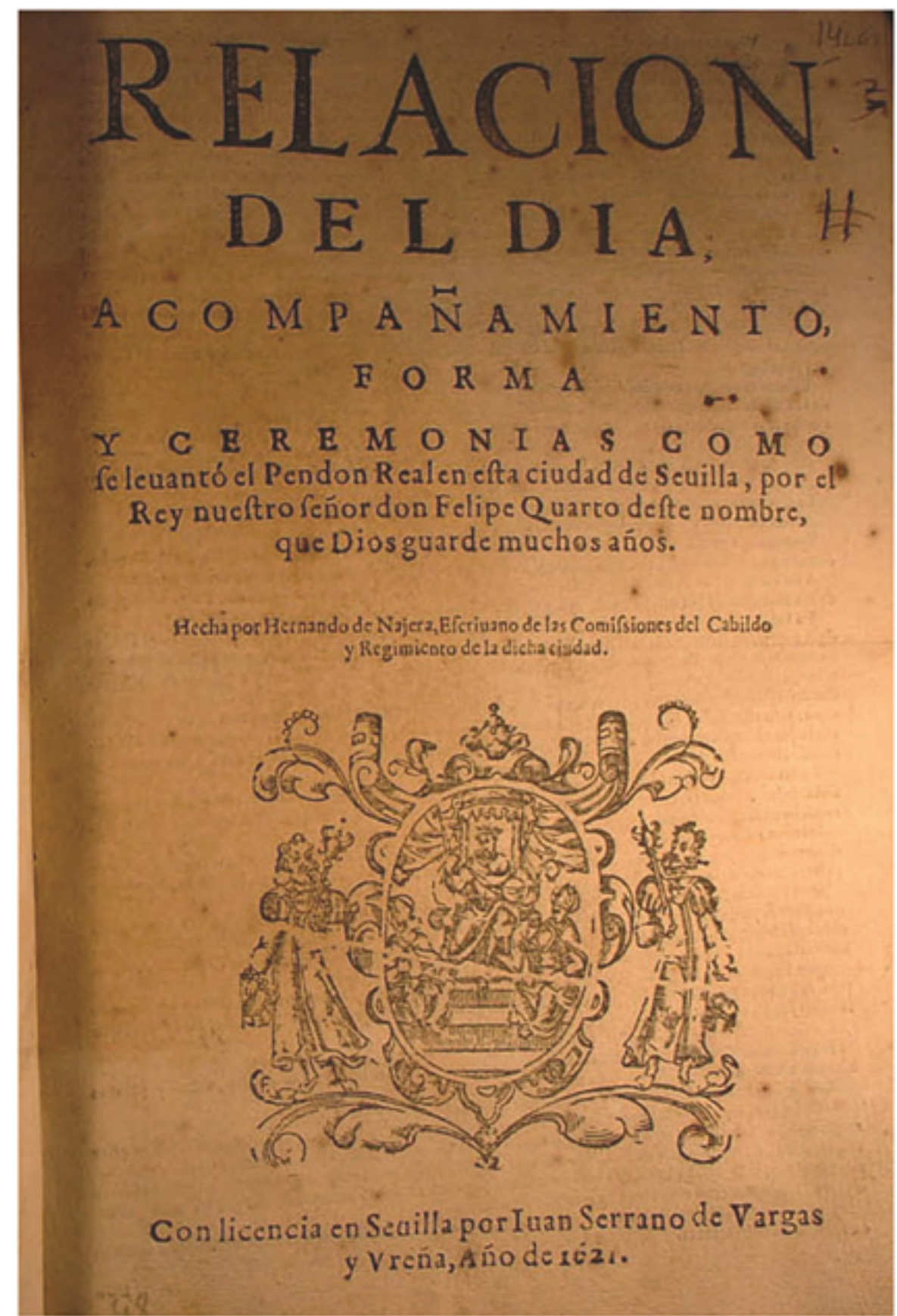

Fig. 6 


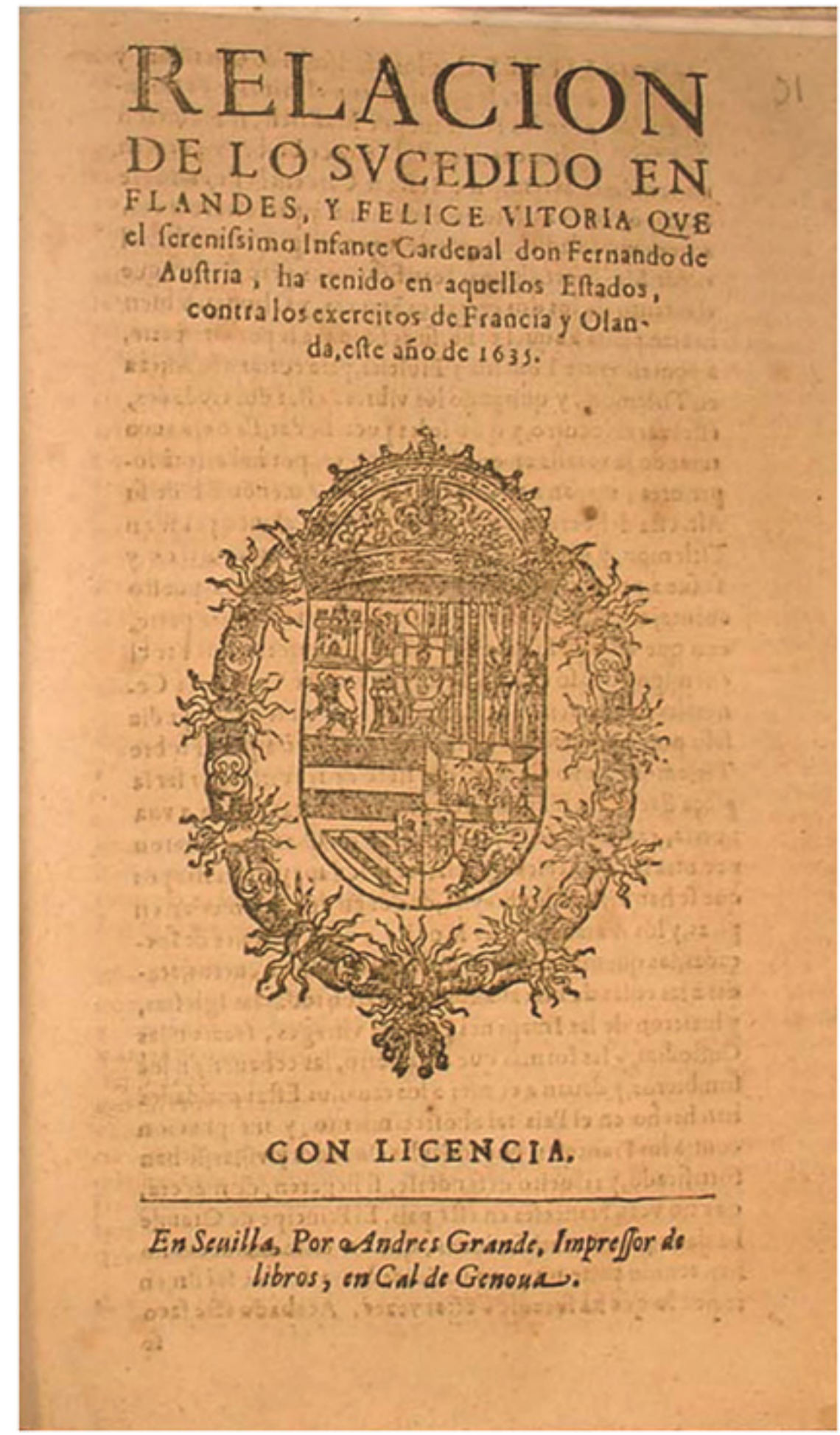

Fig. 7 


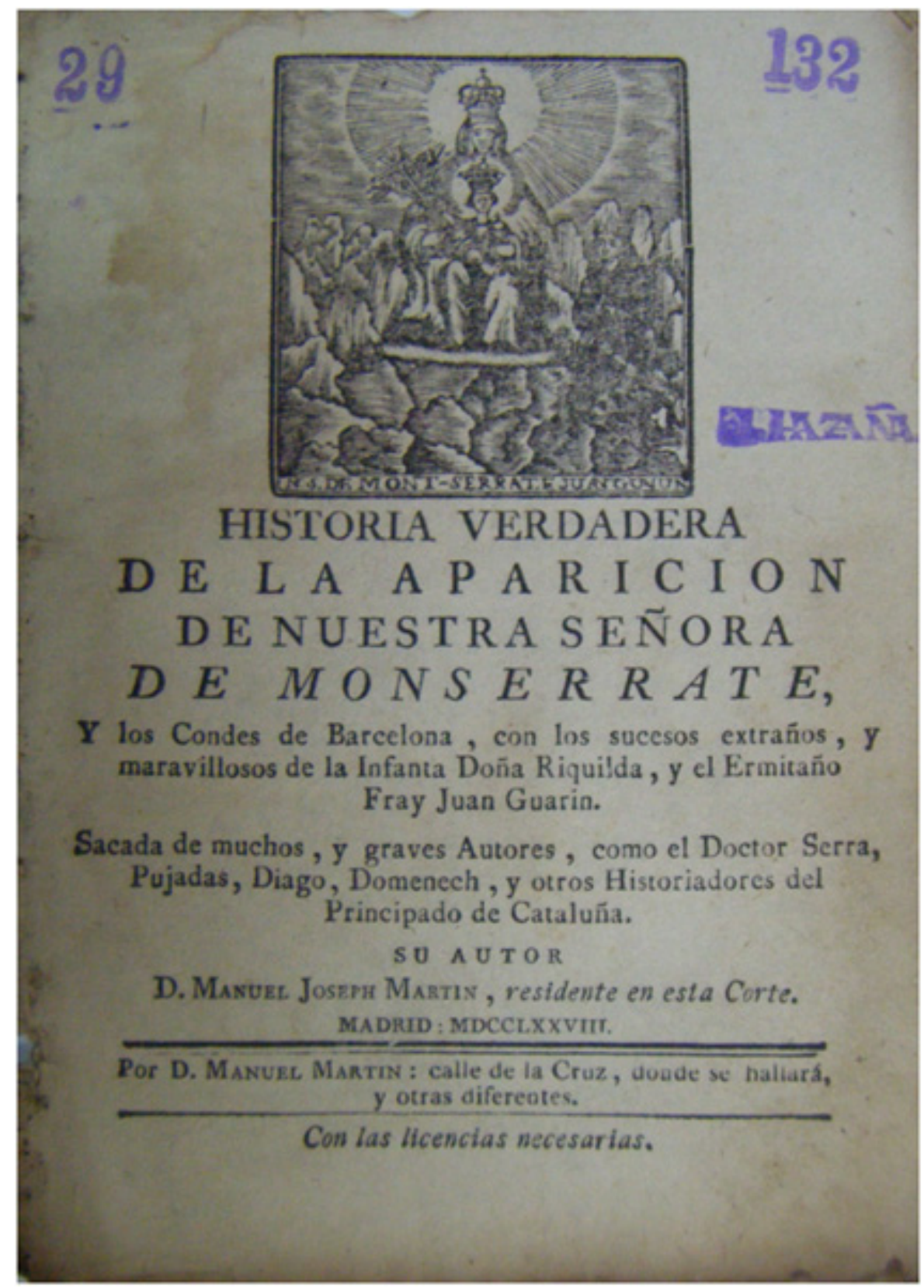

Fig. 8 